\title{
Bioedusiana
}

\section{PENGARUH MODEL PEMBELAJARAN KOOPERATIF TIPE COOPERATIVE INTEGRATED READING AND COMPOSITION TERHADAP HASIL BELAJAR PESERTA DIDIK PADA KONSEP SISTEM PENCERNAAN MAKANAN PADA MANUSIA}

The effect cooperative learning model type cooperative integrated reading and composition of learning outcomes learner on the concept Food in the Human Digestive System.

\section{Neneng Erna ${ }^{1}$, Egi Nuryadin ${ }^{2)}$}

${ }^{1)}$ SMP Islam Nurussalam, Kp Madewangi No. 17 Setiamulya Kec. Tamansari Tasikmalaya - 46196

${ }^{2)}$ Jurusan Pendidikan Biologi FKIP Universitas Siliwangi, Jalan Siliwangi Nomor 24, Tasikmalaya - 46115 Email korespondensi: nenengerna72@gmail.com

\begin{tabular}{|c|c|}
\hline Info Artikel & Abstrak \\
\hline $\begin{array}{l}\text { Keywords: } \\
\text { cooperative integrated reading } \\
\text { and composition, } \\
\text { concept Food in the Human } \\
\text { Digestive System }\end{array}$ & $\begin{array}{l}\text { Penelitian ini bertujuan untuk mengetahui pengaruh model pembelajaran kooperatif tipe cooperative integrated } \\
\text { reading and composition terhadap hasil belajar peserta didik pada konsep Sistem Pencernaan Makanan pada } \\
\text { Manusia. Penelitian dilaksanakan pada bulan Desember } 2012 \text { sampai dengan bulan Maret } 2013 \text { SMA Negeri } 1 \\
\text { Manonjaya. Metode yang digunakan dalam penelitian ini adalah metode true experiment. Populasi penelitian in } \\
\text { adalah kelas XI IPA SMA Negeri } 1 \text { Manonjaya tahun pelajaran } 2012 / 2013 \text { sebanyak } 5 \text { kelas dan sampel yang } \\
\text { digunakan adalah } 2 \text { kelas yaitu kelas XI IPA } 1 \text { dan IPA } 2 \text { yang diambil dengan cara cluster random sampling. } \\
\text { Instrumen yang digunakan dalam penelitian ini adalah tes hasil belajar siswa pada konsep Sistem Pencernaan } \\
\text { Makanan pada Manusia. Tes ini berupa pilihan ganda dengan lima option. Teknik analisis data yang digunakan } \\
\text { adalah uji t. Hasil penelitian menyimpulkan terdapat pengaruh model pembelajaran kooperatif tipe coperative } \\
\text { integrated reading and composition terhadap hasil belajar peserta didik pada Konsep Sistem Pencernaan Makanan } \\
\text { pada Manusia. Penelitian yang selanjutnya, peneliti harus melakukan inovasi agar model pambalajaran kooperatif } \\
\text { tipe cooperative integrated reading and composition ini lebih optimal dan menarik bagi peserta didik dalam memahami } \\
\text { istilah-istilah pelajaran biologi. }\end{array}$ \\
\hline
\end{tabular}

\section{Abstract}

This research aims to know the effect model cooperative learning type cooperative integrated reading and composition of learning outcomes learner on the concept Food in the Human Digestive System. The research was carried out in December 2012 up to March 2013 in SMA Negeri 1 Manonjaya. The methods used in this research is a method of true experiment. The population of this research is the class XI IPA SMA Negeri 1 Manonjaya year 2012/2013 lessons as much as 5 class and the sample used is 2 classes, namely class XI IPA IPA 1 and 2 taken by cluster random sampling. The instruments used in this research is the test results of student learning on the concept of Food in the human digestive system. This is a multiple choice test with five options. Technique of data analysis, the $t$ test is used. Research results concluded there is effect model cooperative learning type cooperative integrated reading and composition of learning outcomes learner on the concept Food in the Human Digestive System. Further research, the researcher must innovate in order to model cooperative learning type cooperative integrated reading and composition is more useful and interesting for the students in understanding the lessons of biology terms.

(C) 2018 Universitas Siliwangi

\footnotetext{
Alamat korespondensi:

Jurusan Pendidikan Biologi FKIP Universitas Siliwangi

Gedung Perkantoran FKIP Lt. 3

Jalan Siliwangi No. 24 Kota Tasikmalaya 46115

HP. 081235955555 (a.n. Romy Faisal Mustofa, M.Pd.)

E-mail: syahla.aini@gmail.com
} ISSN 2477-5193 


\section{PENDAHULUAN}

Pendidikan merupakan hal yang sangat penting dalam kehidupan, baik dalam kehidupan seseorang, keluarga, bahkan bangsa dan negara karena pendidikan merupakan salah satu sarana dimana kita bisa mengetahui dan memahami arti sebuah perjuangan. Perjuangan untuk mencapai kesuksesan memerlukan pendidikan yang tinggi.

Pendidikan dipercaya sebagai alat strategis meningkatkan taraf hidup manusia. Melalui pendidikan manusia menjadi cerdas, memiliki skill, sikap hidup yang baik sehingga dapat bergaul dengan baik pula di masyarakat dan dapat menolong dirinya sendiri, keluarga dan masyarakat. Pendidikan menjadi investasi yang memberi keuntungan sosial dan pribadi yang menjadikan bangsa bermartabat dan menjadikan individunya menjadi manusia yang memiliki derajat. Unsur manusia yang paling penting menentukan keberhasilan pendidikan adalah guru dan peserta didik. Pentingnya faktor guru dan peserta didik tersebut dapat dirunut melalui pemahaman hakikat pembelajaran, yakni sebagai usaha sadar guru untuk membantu peserta didik agar dapat belajar dengan kebutuhan minatnya.

Guru sebagai unsur pokok penanggung jawab terhadap pelaksanaan dan pengembangan proses belajar mengajar, diharapkan dapat meningkatkan kualitas proses belajar mengajar, proses belajar mengajar merupakan inti dari kegiatan transformasi ilmu pengetahuan dari guru kepada peserta didik. Untuk mencapai efektifitas dan efisiensi tersebut, maka diperlukan adanya model pembelajaran yang tepat dalam mencapai tujuan belajar mengajar yang diharapkan.

Dengan menggunakan pembelajaran kooperatif dapat membantu antar siswa untuk lebih memudahkan berkomunikasi dan saling berinteraksi. Dalam model ini siswa diarahkan untuk biasa bekerja sama dengan lingkungan sosialnya, mengembangkan diri dan tanggung jawab secara individual.

Berdasarkan hasil wawancara dengan pendidik di SMA Negeri 1 Manonjaya pada hari senin 10 Desember 2012 diketahui bahwa pendidik di SMA Negeri 1 Manonjaya khususnya pendidik mata pelajaran biologi dalam pengajarannya selalu menggunakan model pembelajaran yang sama. Sehingga peserta didik kurang semangat dalam pembelajarannya, dan suasana di kelas pun pasif.
Dalam kurikulum KTSP, pendidik hanya bertindak sebagai fasilitator, dan peserta didik dituntut lebih aktif dalam proses pembelajaran. Pada mata pelajaran biologi khususnya materi sistem pencernaan makanan pada manusia, banyak peserta didik yang nilainya kurang dari KKM yaitu hanya mencapai rata-rata nilainya 70,3 , sedangkan KKM yang harus dicapai adalah 73 .

Berdasarkan masalah tersebut perlu dicari model pembelajaran yang dapat meningkatkan aktivitas peserta didik, salah satunya adalah melalui penerapan model pembelajaran kooperatif tipe cooperative integrated reading and composition di kelas XI IPA SMA Negeri 1 Manonjaya pada konsep Sistem Pencernaan Makanan pada Manusia, diharapkan adanya keaktifan dalam proses belajar mengajar dan bisa memotivasi peserta didik untuk lebih dapat meningkatkan hasil belajar, sehingga nilai KKM terpenuhi.

Berdasarkan latar belakang masalah tersebut, dapat diidentifikasi masalah sebagai berikut :

1. mengapa hasil belajar peserta didik pada konsep Sistem Pencernaan Makanan pada Manusia di kelas XII IPA masih rendah?;

2. apakah peserta didik dapat mengikuti pembelajaran dengan menggunakan model pembelajaran kooperatif tipe cooperative integrated reading and composition?;

3. apakah peserta didik tertarik dengan pengaruh model pembelajaran kooperatif tipe cooperative integrated reading and composition?;

4. apakah model pembelajaran kooperatif tipe cooperative integrated reading and composition diterapkan untuk menjelaskan konsep Sistem Pencernaan Makanan pada Manusia?; dan

5. apakah model pembelajaran kooperatif tipe cooperative integrated reading and composition dapat meningkatkan hasil belajar peserta didik pada konsep Sistem Pencernaan Makanan pada Manusia?.

Agar permasalahan yang diteliti tidak terlalu meluas, maka penulis membatasi masalah sebagai berikut :

1. penelitian ini hanya untuk mengukur dan mengetahui hasil belajar peserta didik dengan pengaruh model pembelajaran kooperatif tipe cooperative integrated reading and composition; 
2. hasil belajar peserta didik diambil dari tes tulis dengan bentuk soal pilihan ganda yang diukur dari ranah kognitif dan dibatasi pada jenjang pengetahuan, mengingat $\left(C_{1}\right)$, memahami $\left(C_{2}\right)$, dan menerapkan $\left(\mathrm{C}_{3}\right)$;

3. materi yang dibahas hanya pada Sistem Pencernaan Makanan pada Manusia; dan

4. penelitian pengaruh model pembelajaran ini dilakukan di kelas XI IPA SMA Negeri 1 Manonjaya Kabupaten Tasikmalaya tahun pelajaran 2012/2013.

\section{METODE}

\section{Metode Penelitian}

Metode yang digunakan adalah metode true experimen. Menurut Sukmadinata, Nana Syaodih (2010:58) bahwa "Metode penelitian yang digunakan dalam penelitian ini adalah eksperimen murni (true experimental) karena dalam pengujian variabel bebas dan variabel terikatnya dilakukan terhadap sampel kelompok eksperimen dan kelompok kontrol. Subjek-subjek yang diteliti dalam kedua kelompok tersebut diambil secara acak".

\section{Variabel Penelitian}

Variabel bebas dalam penelitian ini adalah Model pembelajaran kooperatif tipe cooperative integrated reading and composition. Variabel terikat dalam penelitian ini adalah hasil belajar siswa.

\section{Definisi Operasional}

a. Hasil belajar adalah perubahan tingkah laku yang dimiliki peserta didik setelah mengalami pengalaman belajar pada konsep sistem pencernaan makanan pada manusia yang ditunjukkan dengan skor setelah mengerjakan tes kognitif yang dibatasi pada aspek pengetahuan, mengingat $\left(C_{1}\right)$, memahami $\left(C_{2}\right)$, dan menerapkan $\left(\mathrm{C}_{3}\right)$;

b. Model pembelajaran kooperatif tipe cooperative integrated reading and composition adalah model pembelajaran yang dikembangkan dalam pengajaran membaca, menulis dan seni berbahasa. Dalam kegiatan ini peserta didik bekerja dalam kelompok yang heterogen.

Model pembelajaran ini memberikan motivasi kepada peserta didik untuk saling bekerja sama satu sama lain setiap peserta didik bertanggung jawab terhadap tugas kelompok, dan setiap anggota kelompok saling mengeluarkan ide-ide untuk memahami suatu konsep dan menyelesaikan tugas sehingga terbentuk pemahaman. Adapun langkah-langkah model pembelajaran kooperatif tipe cooperative integrated reading and composition adalah sebagai berikut :

a. pendidik membagi peserta didik menjadi beberapa kelompok yang anggotanya terdiri dari 4 orang secara heterogen;

b. peserta didik duduk sesuai dengan kelompoknya masing-masing;

c. pendidik memberikan persoalan kepada peserta didik dan masingmasing kelompok mengerjakannya;

d. peserta didik bekerja sama membacakan dan menemukan jawaban terhadap persoalan yang telah diberikan dan ditulis pada kertas jawaban;

e. pendidik memanggil perwakilan dari setiap kelompok untuk mempersentasikan/membacakan hasil diskusi kelompok;

f. peserta didik memberikan tanggapan terhadap jawaban yang diutarakan oleh perwakilan masing-masing kelompok; dan

g. pendidik memberikan penekanan mengenai point-point penting dari materi dan membuat kesimpulan bersama-sama dengan peserta didik.

c. Pembelajaran konvensional (yang digunakan di kelas kontrol) yaitu pembelajaran langsung. Pembelajaran langsung adalah model pembelajaran yang menekankan pada penguasaan konsep atau perubahan prilaku dengan mengutamakan pendekatan deduktif, dengan ciri-ciri yaitu transformasi dan keterampilan secara langsung, pembelajaran berorientasi pada tujuan tertentu, materi pembelajaran yang telah terstruktur, lingkungan belajar yang telah terstrutur dan distruktur oleh pendidik. 
4. Populasi dan Sampel

a. Populasi

Populasi dalam penelitian ini adalah seluruh kelas XI IPA SMA Negeri 1

Manonjaya sebanyak 5 kelas, tiap kelas terdiri dari 30 orang populasi yang dinggap homogen berdasarkan pada nilai rata-rata raport mata pelajaran biologi semester 2 tiap kelas.

b. Sampel

Sampel yang digunakan sebanyak 2 kelas yang diambil dengan cara cluster random sampling.

5. Desain Penelitian

Desain penelitian yang digunakan dalam penelitian ini adalah desain kelompok kontrol pratest-pascatest beracak (Randomized PretestPosttest Control Group Design) (Sukmadinata, Nana Syaodih. 2010:204).

\section{Kelompok}

Acak A (KE

Acak B (KK)

$\begin{array}{ccc}\text { Pratest } & \text { Perlakuan } & \text { Pascatest } \\ \mathrm{O}_{1} & \mathrm{X} & \mathrm{O}_{2} \\ \mathrm{O}_{1} & & \mathrm{O}_{2}\end{array}$

Keterangan :

\begin{tabular}{|c|c|}
\hline $\mathrm{KE}$ & $\begin{array}{l}\text { Kelompok } \begin{array}{r}\text { Eksperimen } \\
\text { (menggunakan model }\end{array} \\
\text { pembelajaran kooperatif tipe } \\
\text { cooperative integrated reading and } \\
\text { composition. }\end{array}$ \\
\hline KK & $\begin{array}{l}\text { Kelompok Kontrol (diberi } \\
\text { perlakuan seperti biasanya) }\end{array}$ \\
\hline $\mathrm{O}_{1}$ & Pengukuran awal \\
\hline$X$ & $\begin{array}{l}\text { Perlakuan (treatment) dengan } \\
\text { menggunakan model } \\
\text { pembelajaran }\end{array}$ \\
\hline & $\begin{array}{l}\text { kooperatif tipe cooperative } \\
\text { integrated } \\
\text { reading and composition. }\end{array}$ \\
\hline $\mathrm{O}_{2}$ & Pengukuran akhir \\
\hline
\end{tabular}

\section{Teknik Pengumpulan Data}

Teknik pengumpulan data dalam penelitian ini adalah teknik tes tertulis. Karena dalam penelitian penulis melakukan observasi dengan menggunakan instrumen berupa tes tertulis dalam bentuk pilihan ganda dengan 5 option.

\section{Instrumen penelitian}

Instrumen yang digunakan dalam penelitian ini adalah tes hasil belajar peserta didik pada konsep sistem pencernaan makanan pada manusia dengan jumlah soal sebanyak 50 soal. Tes berbentuk pilihan ganda dengan 5 option. Aspek yang diukur hanya dominan kognitif dan dibatasi hanya pada jenjang pengetahuan, mengingat $\left(C_{1}\right)$, memahami $\left(C_{2}\right)$, dan menerapkan $\left(C_{3}\right)$. Selanjutnya soal yang jawabannya benar diberi skor satu (1) dan jawaban yang salah diberi skor nol (0).

8. Uji coba instrument

Uji coba instrumen dilaksanakan di kelas XII IPA 2 SMA Negeri 1 Manonjaya Kabupaten Tasikmalaya, diperoleh 36 soal yang valid yang nantinya digunakan dalam penelitian.

9. Analisis data

a. Uji Prasyarat Analisis

1) Uji Normalitas

Menggunakan Uji Chi Kuadrat ( $\left.x^{2}\right)$.

Data yang di uji meliputi pretest, postest, gain dari kelas kontrol, dan pretest, postest, gain dari kelas eksperimen

2) Uji Homogenitas

Menggunakan Uji $\mathrm{F}_{\text {maximum. }}$. Data yang di uji meliputi pretest-postest kelas kontrol, pretest-postest kelas eksperimen, dan gain kelas kontrol - gain kelas eksperimen.

\section{b. Uji Hipotesis}

Karena semua data berdistribusi normal dan homogen maka analisis dilanjutkan ke langkah pengujian hipotesis dengan uji statistik parametrik (uji t). Data yang di uji meliputi pretest-postest kelas kontrol, pretestpostest kelas eksperimen, dan gain kelas kontrol - gain kelas eksperimen.

\section{HASIL DAN PEMBAHASAN}

Selama penelitian, peneliti menggunakan dua kelas sebagai kelas eksperimen dan kelas kontrol. Kelas eksperimen pada proses pembelajarannya menggunakan model pembelajaran kooperatif tipe cooperative integrated 
reading and composition sedangkan kelas kontrol menggunakan model pembelajaran langsung.

Hasil belajar peserta didik di kelas eksperimen yang menggunakan model pembelajaran kooperatif tipe cooperative integrated reading and composition dan kelas kontrol yang menggunakan model pembelajaran langsung menunjukan hasil yang berbeda, tidak hanya dalam proses pembelajarannya tapi dapat dilihat dari nilai pretest, post-test, dan gain kedua kelas tersebut. Untuk melihat hasil pembelajaran dari kedua kelas tadi, disajikan dalam gambar berikut ini (gambar 1):

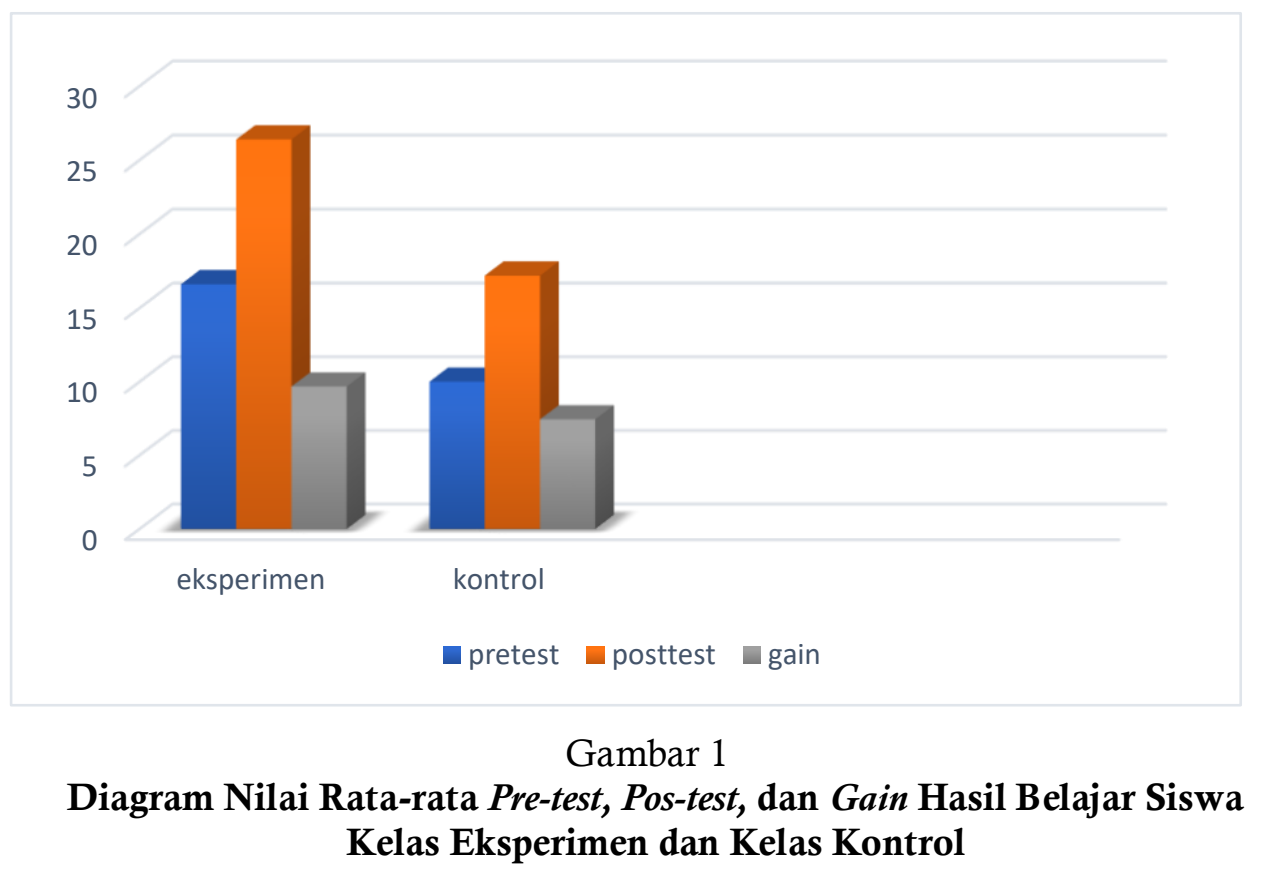

Gambar 1 menjelaskan hasil pre-test dengan post-test di kelas eksperimen dan kelas kontrol. Berdasarkan gambar di atas diketahui bahwa rata-rata gain di kelas eksperimen adalah 9, 67 sedangkan rata-rata gain di kelas kontrol adalah 7,44 . Hal tersebut menunjukan gain di kelas eksperimen lebih besar dari gain di kelas kontrol dan rata-rata post test di kelas eksperimen 26,39, sedangkan rata-rata post-test di kelas kontrol adalah 17,19 .

Dari hasil penelitian maka ditemukan adanya pengaruh model cooperative integrated reading and composition terhadap hasil belajar peserta didik pada konsep sistem pencernaan makanan pada manusia. Hal ini dikarenakan model pembelajaran kooperatif tipe cooperative integrated reading and composition membuat siswa lebih aktif, kreatif dan menemukan pengetahuan melalui pengalaman mereka sendiri.

Kelebihan model pembelajaran kooperatif tipe cooperative integrated reading and composition adalah cooperative integrated reading and composition sangat tepat untuki meningkatkan keterampilan peserta didik dalam menyelesaikan masalah, dominasi pendidik dalam pembelajaran berkurang, peserta didik termotivasi pada hasil pembelajaran secara diteliti karena bekerja dalam kelompok, para peserta didik dapat memahami makna soal dan saling mengecek pekerjaannya, membantu peserta didik yang lemah.

Kekurangan model pembelajaran kooperatif tipe cooperative integrated reading and composition adalah pada saat persentasi hanya siswa yang aktip tampil, tidak semua peserta didik bisa mengerjakan soal dengan teliti.

Jika dibandingkan dengan model pembelajaran langsung, peserta didik kurang bersemangat karena peneliti hampir mendominasi pembelajaran. Peserta didik hanya mendengarkan dan menerima semua informasi dari peneliti saja, sedangkan peserta didik tidak 
berperan dalam pembentuk pengetahuannya sendiri.

\section{SIMPULAN, SARAN, DAN REKOMENDASI}

Berdasarkan hasil analisis data dan pengujian hipotesis, maka penulis memperoleh kesimpulan bahwa ada pengaruh pembelajarannya menggunakan model pembelajaran kooperatif tipe cooperative integrated reading and composition terhadap hasil belajar pada konsep Sistem Pencernaan Makanan Pada Manusia di kelas IPA SMA Negeri 1 Manonjaya. Selama proses pembelajaran berlangsung terlihat perkembangan siswa menjadi aktif, baik dalam bertanya, diskusi bersama teman sekelompok dan juga dalam mengemukakan pendapat. Saran dalam penelitian ini untuk menggunkan model pembelajaran kooperatif tipe cooperative integrated reading and composition peserta didik harus diberikan motivasi untuk gemar membaca materi biologi.

\section{DAFTAR PUSTAKA}

Arikunto, Suharsimi. (2006). Prosedur Penelitian Suatu Pendekatan Praktik. Jakarta: Rineka Cipta.

Dimyati dan Mudjiono. (2010). Belajar dan Pembelajaran. Jakarta: PT. Rineka Cipta.

E. Robert, Slavin. (2005). Cooverative Learning. Bandung: Nusa Media.

Huda, Miftahul. (2011). Cooperative Learning Metode, Teknik, Struktur dan Model Penerapan. Yogyakarta: Pustaka Pelajar.

Isjoni. (2010). Pembelajaran Kooperatif Meningkatkan Kecerdasan Komunikasi Antar Peserta Didik. Yogyakarta: Pustaka Pelajar.

Lie, Anita. (2008). Cooperative Learning. Jakarta: PT Grasindo.

Sharan, Shlomo. (2012). The Handbook of Cooverative Learning. Yogyakarta : Familia

Slameto. (2010). Belajar dan Faktor-faktor yang Mempengaruhinya (Edisi Revisi). Jakarta: PT. Rineka Cipta.

Sukmadinata, Nana syaodih. (2009). Metode Penelitian Pendidikan. Bandung: PT Rosda Karya.

Suprijono, Agus. (2011). Cooperative Learning Teori dan Aplikasi PAIKEM. Yogyakarta: Pustaka Pelajar.

Suyitno, amin. (2005). Pengadopsi pembelajaran cooperative integrated reading and composition dalam meningkatkan keterampilan siswa menyelesaikan soal cerita seminar nasional F.MIPA UNNES.
Syah, Muhibin. (2010). Psikologi Pendidikan dengan Pendekatan Baru (Edisi Revisi). Bandung: PT. Remaja Rosdakarya.

Trianto. (2011). Mendesain Model Pembelajaran Inovatif Progresif. Jakarta: Prenada Media Group.

Widaningsih, Dedeh. (2011). Evaluasi Pembelajaran Matematika. Tasikmalaya: FKIP Universitas Siliwangi.

Yamin, Martinis. (2008). Paradigma Pendidikan Kontruktivistik. Jakarta: Gaung Persada Press 
Neneng Erna, Egi Nuryadin / Bioedusiana 3 (2) (2018) 